\title{
O Marxismo e a crítica da Política Internacional: um estudo sobre as instituiçõoes de um mundo globalizado
}

\author{
Bruno M. Falcetti* \\ * Universidade Federal de São Paulo, Brasil
}

\begin{abstract}
Resumo
O presente artigo tem a intenção de levantar elementos importantes do marxismo para uma crítica da política internacional e aplicá-los a um estudo sobre a superestrutura internacional, bem como os elementos íntimos a tal estrutura. Encontra-se dividido em 4 itens fundamentais: (I) uma discussão sobre os elementos necessários para uma teoria das relações internacionais (o conceito sobre Estado e a guerra); (II) uma discussão sobre a crítica marxista das tradições clássicas nas Relações Internacionais; (III) a construção de uma arena para análise sob a ótica marxista; (IV) um ensaio sobre as instituições internacionais e globalização, fundamentado pelos elementos articulados ao longo do artigo.
\end{abstract}

Palavras-chave: Marxismo; política internacional; relações internacionais

\begin{abstract}
The present paper aims to raise important elements of Marxism for a critique of international politics and apply them to a study on the international superstructure. This paper is divided into 4 fundamental items: (I) a discussion on the necessary elements to an international relations theory (the concept of State and war); (II) a discussion on the Marxist criticism of classical traditions in International Relations; (III) the construction of an arena for analysis from the Marxist point of view; (IV) an essay on international institutions and globalization, based on the elements articulated throughout the paper.
\end{abstract}

Keywords: Marxism; international politics; international relations 


\section{Introdução}

Nem tanto por força das tendências residuais, a derrocada soviética e as infindáveis tentativas de universalização do liberalismo, resultantes do encerramento da Guerra Fria - que, de certa forma, serviu como centelha para sua desventura -, e mais por circunstância, como afirma Espinosa (2014), de uma saturação de autores e seguidores que o descaracterizaram, transformando-o mais em doutrina do que ciência - ao fazer de seus equívocos uma cartilha dogmática - , o século xxi recebe o marxismo face ao vilipêndio produzido pelos próprios simpáticos (Espinosa, 2014, p. 285).

$\mathrm{O}$ que aqui é levado a protesto, quando referimo-nos à parte dos marxistas vulgares, são os que voltaram-se à história e aos elementos fatídicos buscando teorizá-los com certo grau de abstração intelectual — por vezes, contaminados pela parcela não marxista das Ciências Sociais, inclinados, como Nicos Poulantzas (apud Codato, 2008 , p. 82) critica contundentemente, pelo devaneio de constituir leis gerais - , avizinhando-se mais ao real pensado, tomando distância do real concreto. O problema em fazê-lo é que passa mais a obedecer a uma especulação com vistas ideológicas particulares do que, de fato, à ciência. A história é concreta, diferente da especulação abstrata e, portanto, tal qual o indivíduo é, ao mesmo tempo, abstrata e concreta (Krader, 1983, p. 266).

A razão da aglutinação entre doutrina e ciência na tradição marxista dá-se por seu caráter práxico, inscrito por Marx, ao pensar o filósofo como aquele que deve, não apenas se pôr a investigar o mundo, mas também transformá-lo (Marx, 1888, pp. 69-72). O que se pretendia era não um simples deslocamento da filosofia para o socialismo científico, buscando superá-la, mas um "programa prático complexo" que, para sua realização, far-se-ia necessária a prática (Mészáros, 1983, p. 157). Isso indica que a mudança não poderia ocorrer pura e simplesmente no mero terreno científico, mas nas práxis, ou seja, "não se pode suplantar a filosofia sem realizá-la" (Marx apud Mészáros, 1983, p. 157). O que ocorre é que, note bem, ao longo das citações eufóricas, seu caráter doutrinário foi descolado do "socialismo científico", saturando aquele primeiro, empobrecendo-o e transformando-o em uma literatura que exalta as imprecisões teóricas em Marx (Anderson, 1985, pp. 11-36). Os excessos de seus seguidores separaram a tradição marxista da realidade, esmaecendo sua capacidade de prever os problemas que viriam a, por exemplo, mitigar o bloco soviético e, portanto:

[O marxismo] não foi capaz de entender a financeirização da economia mundial, que reconfigurava a própria formação de valores, associada a fenômenos como o surgimento de uma nova classe média, a perda de relevância da classe operária, a emergência do consumismo desenfreado e... provocava mudanças estruturais no Estado, nas classes sociais e no próprio capitalismo (Espinosa, 2014, p. 286).

O fracasso dos soviéticos e a desmoralização do marxismo, em crise epistemológica, nos leva a pensar novamente os fundamentos do marxismo não como parte de uma expressão utópica, fruto de alguns de seus expoentes, mas como um esforço de recuperar a estrutura lógica do materialismo histórico e dialético, dialogando com os 
novos paradigmas e, finalmente, reassumir o compromisso de fazer ciência sem virar as costas para a ética da igualdade (Espinosa, 2014, p. 291).

Face ao tema deste trabalho e às discussões das linhas anteriores, uma série de trabalhos trouxeram o marxismo ao palco de debates sobre as Relações Internacionais, descaracterizando a atenção principal de Marx - o modo de produção capitalista, suas contradições e expansão - buscando edificar uma teoria da política internacional genérica e repleta de limitações. A crítica que se monta em torno deste debate é que, por um lado, os marxistas têm ignorado a importância do Estado na dinâmica das Relações Internacionais - que, no limite, é o agente básico das Relações Internacionais (Cox, 2007, p. 113) e, por outro, as correntes ortodoxas das Relações Internacionais negligenciam a importância das classes na análise da política internacional. Os esforços dos marxistas, neste sentido, têm sido os de resgatar a lógica do materialismo dialético e histórico - voltada à economia, não se afastando do seu método e léxico tradicional, atualizando-o face aos novos paradigmas que se apresentam em nível global, em vista de empregar o marxismo na análise das Relações Internacionais -, estendendo-se ao alcance global do capitalismo, à projeção da luta de classes no cenário mundial e às contradições que dinamizam o sistema de Estados (Messari \& Nogueira, 2005, pp. 160-111).

A ortodoxia das Relações Internacionais, além de ignorar o papel ontológico das classes, pode ser problematizada pela ausência de historicidade. Ao negligenciar as classes, como sujeito histórico, também aponta o Estado como objeto estático, fruto não somente da tradição positivista e da larga influência das ciências naturais, mas do congelamento dessas abordagens no plano abstrato. Requer, para nós, um exercício mais extenso e rigoroso: é fato que se parte de uma caótica, dinâmica e complexa "realidade", que nada diz, a fim de compreendê-la; para tanto, eleva-se aquilo que se captura ao plano abstrato, para a dimensão que é passível de categorização e, por fim, retorna-se ao concreto e, desta vez, haverá um olhar mais apurado sobre a dinâmica da realidade. A dinâmica da realidade não pode ser capturada por meras abstrações, tampouco pode ser por nós perfeitamente apreendida e, a depender do método, contudo, é possível preservar sua lógica.

Faremos, portanto, um exercício, ainda que limitado por tantos mil caracteres, de entender a dinâmica que há por trás da relação entre as grandes potências e a periferia do sistema internacional. Ao fim e ao cabo, neste trabalho, temos as intenções de: (1) entender papel do marxismo na análise da política internacional, sua crítica e os elementos importantes que a tradição fornece para a análise; (2) apreender as contradições produzidas no âmbito da estrutura de Estados - não deixando de considerar nem o primado ontológico de classes do marxismo, nem o primado do Estado das teses ortodoxas de Relações Internacionais, uma vez que nosso objetivo é entendê-los como primados que se complementam e interagem inscritos na expressão anárquica do sistema internacional. Para fazê-lo, pretendo levantar as discussões sobre os elementos inerentes à ortodoxia das Relações Internacionais, resgatando sempre o primado de classes e o caráter estrutural do marxismo; (3) entender, como sugere o título, a dinâmica das instituições internacionais como produto de uma relação dialética estrutural que configura um subsistema composto de estrutura própria, in- 
ternalizando contradições mais particulares, ainda que absorvendo partes daquelas que a produzem.

Pensando a organização deste raciocínio, a hipótese que aqui se apresenta é que, ao configurar uma estrutura particular, uma instituição internacional é capaz de reproduzir uma organização de dependência análoga do Sistema Internacional, onde alguns Estados colocar-se-ão na condição de centralidade econômica, projetando o poder e os interesses de sua classe dominante doméstica, absorvendo recursos de uma periferia (que se configura dentro da estrutura de poder reproduzida por uma instituição reificada), permitindo-nos conceituar este paradigma como análogo a um fenômeno cosmológico - imagine que, neste caso, aqueles Estados que compõem a periferia, orbitam, parafraseando a cosmologia, sob o espectro de influência econômica e política daqueles que compõem os Estados chamados, na perspectiva marxista, de centrais. Se essa hipótese se sustentar dentro das bibliografias, entrevistadas ao longo deste estudo qualitativo, poderemos explicar uma série de contradições que envolvem o fenômeno globalizante, o empobrecimento e a negação da globalização pela classe trabalhadora.

\title{
2. Teoria das Relações Internacionais: há espaço para o marxismo?
}

\begin{abstract}
A isso nos incitam alguns clamorosos acontecimentos recentes que, contra o modo tradicional e tornado acriticamente convencional de consideraras relações entre Estados por parte da doutrina marxista corrente, levam a que se ponha, com respeito a esse problema [teoria marxista do Estado], o mesmo tipo de questão que foi posta a respeito das relações internas: "Existe uma teoria marxista das relações internacionais? Se existe, qual é ela?” (Bobbio, 2006, p. 222).
\end{abstract}

É com esta pergunta que Bobbio provoca uma discussão sobre a posição da tradição marxista dentro do debate da teoria das relações internacionais. É fato que Marx não se empenhou em elaborar uma teoria voltada para a política internacional, entretanto e guardadas as proporções, isso não significa que o marxismo nada tenha a considerar sobre ela, muito pelo contrário: as visões estruturais sobre o mundo têm muitas explicações alternativas a oferecer para a disciplina (Sarfati, 2005).

Retomando a discussão inicial deste item, é preciso compreender os motivos que articulam a indagação de Bobbio (2006). Para o autor, o marxismo é essencialmente uma teoria econômica, desprovida de uma teoria do Estado, da política e, por fim, da guerra, o que seriam, segundo ele, elementos necessários para a consolidação de uma teoria das Relações Internacionais. O objetivo deste trabalho não permite debruçarmo-nos em ensaios sobre a política e a guerra, portanto, nossa concentração estará constantemente direcionada às lutas de classe e a um ensaio sobre a teoria marxista do Estado de forma a compreender a relação entre estes e o Sistema Internacional.

Em síntese, tratando-se das unidades políticas, Bobbio (2006) argumenta que os marxistas estiveram fortemente inclinados em entender as relações de força e lutas de classes dentro do Estado, onde se desenrola o domínio daquele que detém o poder econômico e/ou político sobre aquele que não o tem, projetando sua força em prol da 
manutenção da ordem social e reprodução do modo de produção capitalista. Nesse sentido, a grande lacuna que o autor observa é que o Estado possui duas faces: aquela que se volta para dentro e a outra que se volta para fora, ou seja, para a relação com outros Estados. Note bem que uma dessas faces é a de dominação política e jurídica internamente reconhecida, bem como o monopólio "legítimo" da força, enquanto a outra não, isso porque está em concorrência relativa de força com outros - e num regime de livre disputa com os demais Estados, o uso da força como instrumento é imperativo moral para obter os efeitos desejados no cenário internacional (Bobbio, 2006).

Ao fim e ao cabo, os expoentes marxistas da teoria do Estado estiveram inclinados sobre sua dimensão interna, a despeito disto, a lacuna que limita os marxistas no debate das Relações Internacionais é a ausência de uma discussão precisa sobre a face externa da unidade estatal. Dada a compatibilidade epistemológica entre o marxismo e a ortodoxia de Relações Internacionais - em termos de que a estrutura determina o comportamento dos agentes - o nosso esforço, na primeira subdivisão deste tópico, será o de entender a complementaridade ontológica entre classes sociais e Estados, compreendendo este último como o meio principal de contato dos antagonismos de classe domésticos com as classes dominantes externas.

Neste processo, ambos os objetos ontológicos (classe e Estado) serão indispensáveis e nos concentraremos em entender como a luta de classes se condensa dentro do Estado e se projeta para o sistema internacional.

Note que Bobbio (2006), retomando rapidamente, questiona amplamente e considera pretensiosa a afirmação da existência de uma Teoria Marxista das Relações Internacionais - visto que a esta última lhe falta elementos que configurem uma teoria das Relações Internacionais. O que pretendo a seguir é, portanto, recuperar um pouco da bibliografia de autores marxistas inclinados a discutir o Estado e ir além: tentar estabelecer um diálogo que conecte as faces interna e externa de uma unidade estatal, o que nos permitirá entender como as unidades estatais projetam-se para fora.

No que diz respeito à estrutura, dedicarei alguns subitens a seguir para organizar as reflexões que propus no parágrafo anterior. É importante recuperar que aquelas lacunas expostas por Bobbio, que nos impedem de seguir viagem, serão alvo das minhas discussões nas próximas linhas onde, por sugestão do professor Dr. Antônio Roberto Espinosa ${ }^{[1]}$, tentarei encontrar pontos de diálogo fundamentais com outras tradições que, fundamentalmente e tão somente, nos permitam seguir caminho na análise da política internacional. Por fim, face ao propósito deste trabalho, devo deixar claro que procurarei ser o mais objetivo possível sem, contudo, deixar de lado observações importantes, deixando detalhes e pormenores para uma outra ocasião.

1. Professor de Teoria Política e Política Internacional na Escola Paulista de Política, Economia e Negócios da Universidade Federal de São Paulo (EPPEN-UNIFESP). 


\section{O Estado "de baixo para cima, de dentro para fora"}

O processo de produção, por meio do trabalho, expressa-se por si em uma dupla relação: (I) a natural, no sentido de que se transforma a natureza na realização do trabalho; e, (II) social, porque a cooperação entre os indivíduos está implícita em todo modo de trabalho. Um modo de produção, para Krader (1983), por mais particular que seja, determina a condição da sociedade (a forma como a qual se organiza) e não o contrário (Krader, 1983, p. 267). Portanto, o modo de produção constitui a base da sociedade ${ }^{[2]}$ - ou seja, uma base que é determinada economicamente.

É sabido que Marx não se preocupou em escrever uma teoria geral do Estado, no aspecto severo da palavra. Isso não significa que Marx não tenha refletido ou discutido sobre este problema, mas não logrou uma obra especificamente para tratar de suas generalidades. Portanto, para preencher esta lacuna e permitir que sigamos viagem, vamos nos apoiar sobre as linhas gerais que o marxismo dispõe.

Antes de seguir, creio que ao leitor deve restar uma dúvida: qual a relação entre o segundo e o primeiro parágrafo? Pois bem, entender o que é modo de produção e de qual estamos necessariamente falando ${ }^{[3]}$ nos ajudará a entender a ideia de Estado como apêndice da sociedade. Neste sentido, as relações de classe que compõem a base de uma sociedade materializam a lógica na qual os indivíduos de uma classe economicamente dominante projetam seus interesses sobre as classes dominadas (Krader, 1983, p. 277). Desta lógica, ainda que viável, parte um equívoco fundamental para iniciar uma discussão sobre o Estado: o ato de legislar (ou governar) repousar-se-ia sobre o desejo dos homens ${ }^{[4]}$, de acordo com o pensamento hegeliano.

A crítica marxista que se constrói em torno desta discussão reside, nas palavras de Bobbio (2006), em fazer de sujeito aquilo que deveria ser predicado. Para Hegel, o Estado é fruto da vontade do homem e, portanto, tem um fim em si mesmo - em outras palavras, os indivíduos são os componentes da configuração estatal pelo simples desejo da dominação (Hegel apud Bobbio, 2006). Partindo da lógica de que o indivíduo abstrato (o Estado) não tem história, enquanto o indivíduo concreto (o homem) não somente está na história como é a única base para toda a realização material, ou seja, toda realidade social (material e histórica) (Krader, 1983, p. 277), Marx rechaça a concepção hegeliana:

[...] para o filósofo não-especulativo a pera é uma fruta, ao passo que para o filósofo especulativo a fruta põe-se como pera, [...] a esta operação, concebe-se a substância como sujeito (enquanto deveria ser o predicado) e o fenômeno como predicado (enquanto deveria ser sujeito) [...] formado assim o caráter do método hegeliano (Marx \& Engels apud Bobbio, 2006, p. 153).

2. Note que modo de produção não é sinônimo de totalidade da sociedade, mas sua base econômica, estando esta base conectada com a superestrutura da sociedade.

3. Em poucas palavras: falamos do modo de produção capitalista (da acumulação do capital e absorção do excedente de trabalho pela burguesia) e é dentro das relações de produção capitalista que se materializa o objeto deste item.

4. Refiro-me aqui à filosofia do direito de Hegel (Bobbio, 2006, p. 152). 
Em outras palavras, é correto pensar o Estado como substância abstrata, como pressuposto da sociedade. Para tanto, este processo leva Marx a concentrar maior atenção sobre o problema da sociedade civil do que o do Estado. Entretanto, Bobbio não deixa de considerar a possibilidade de que, partindo desta concepção inicial, é possível deduzir e sistematizar algumas linhas gerais a partir das ocasionais abordagens e críticas de Marx, principalmente ao negar a concepção hegeliana - argumentando, substancialmente, que o Estado existe, pois a sociedade existe.

Portanto, Marx considera o Estado como um conjunto de instituições que aglutina toda a "violência concentrada e organizada da sociedade" (Marx apud Bobbio, 2006, p. 155) que configura o poder criador e mantedor do Estado e, portanto, é a reificação de um conjunto de relações. Partindo deste último pressuposto, começaremos a delinear em linhas gerais o problema do Estado, mais precisamente na sua configuração capitalista/burguesa.

Note que até este momento captamos um raciocínio fundamental: o Estado está condicionado às relações econômicas, isso é, sua existência está relacionada à sociedade civil - onde formam-se as classes e seus antagonismos. Estamos, assim, partindo da consideração de que, via de regra, a classe economicamente dominante não é "aquela que governa, mas é aquela que domina" (Kautsky, 1903, p. 13) porque, no fim das contas, a burguesia está bem representada e indiretamente impregnada nas instituições do Estado pois, de acordo com Miliband, falando em prevalência econômica, a burguesia tem as condições e meios necessários para recrutar representantes (Miliband, 1972, pp. 74-79) (com forte capital político) dos interesses comuns da burguesia para a elite política ${ }^{[5]}$.

Mesmo partindo deste pressuposto, não se pode ignorar o que Poulantzas chama de autonomia relativa do Estado - isso quer dizer que o Estado, como expressão material de um conjunto de relações, não possui um bloco homogêneo no poder ${ }^{[6]}$, tampouco organizado ou uniforme, isso acontece porque, além das relações de força entre Estado e as classes dominadas, há relações de força entre as frações da classe dominante dentro dos aparelhos estatais e, por fim, relações de força entre os próprios aparelhos do Estado (Poulantzas, 2000, p. 162).

[...] o processo econômico é luta de classes e, portanto, relações de poder (e não somente poder econômico)... mas também poderes político-ideológicos... essas relações de poder, lastreadas na produção da mais-valia e na ligação aos poderes político-ideológicos, materializam-se nas instituições-aparelhos específicos que são as empresas-fábricas-unidades de produção, lugares de extração da mais-valia e de exercício desses poderes (Poulantzas, 2000, p. 41).

Perceba então que as relações de poder político-ideológico estão lastreadas, parafraseando Poulantzas, nas relações de poder econômico (extração da mais-valia).

5. Não me coloco aqui na posição de negar que a classe economicamente dominante tenha governado diretamente e, tampouco, não nega que alguns elementos da classe dominada tenham permeado os aparelhos do Estado, mas deixarei esta discussão para outra ocasião.

6. Quando falo em bloco no poder, assim como Poulantzas, refiro-me à elite política, aos funcionários do Estado e todo o corpo de indivíduos que ocupam os cargos públicos (contratados ou eleitos). 
Esta afirmação inscreve uma relação simbiótica mutualista em que essas relações de

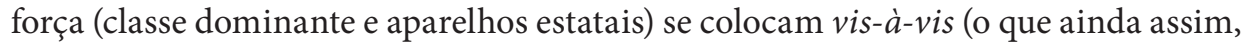
não faz cair por terra as contradições internas do Estado e a noção de autonomia relativa).

Poulantzas destaca, ao longo do raciocínio, três aparelhos fundamentais: o repressivo, o ideológico e o econômico - que têm, respectivamente, as funções de (1) impedir que antagonismos de classe terminem por dissolver a ordem social, (2) moldar e formar o pensamento e (3) realizar o acumulo de capital, que ocorre a nível privado, entretanto, preservando a articulação com o ente público (Poulantzas, 2000, pp. 30-45).

Os aparelhos conceituados acima são meramente descritivos e indicativos pois, segundo Poulantzas, as relações de forças entre eles fazem com que, muitas vezes, acumulem ou permutem funções uns dos outros e até, por vezes, entram em conflito (Poulantzas, 2000, pp. 30-45). Esse jogo de contradições produz dois efeitos importantes e que se complementam: em primeiro, faz com que não se concentre uma força homogênea e, em segundo, essa cadeia de contradições (que deriva das relações de força entre os indivíduos no poder, entre os aparelhos e entre Estado e massas) produz uma síntese geral, desta cadeia deriva a lógica de autonomia relativa do Estado, visto que as forças não se sustentam num bloco perfeitamente coeso (Poulantzas, 2000, pp. 150-167). Partindo do pressuposto de que estes últimos dois elementos são complementares, é de se notar que o Estado, por vezes, e ainda que em baixíssima intensidade, cede a alguns interesses das massas e o estado aparente de ambiguidade esmaece as percepções das reais intenções do ente estatal ${ }^{[7]}$.

Observa-se ao longo dessas informações, ainda que tortuosas, que os aparelhos do Estado são de suma importância para a constituição de uma ideologia hegemônica no contexto das contradições socioeconômicas visto que, para Poulantzas, a hegemonização não absorve simplesmente um

[...] sistema de ideias ou de representações [mas também] uma série de práticas materiais extensivas aos hábitos, aos costumes, ao modo de vida dos agentes, e assim se molda como cimento no conjunto das práticas sociais, aí compreendidas as práticas políticas e econômicas (Poulantzas, 2000, p. 33).

A ideologia, portanto, divide papel fundamental com a repressão como mantedora da ordem, visto que, seguindo a lógica gramsciana, é mais fácil permear um conjunto de concepções morais e ideológicas do que alienar pela agressão bruta.

Em suma, podemos considerar finalmente que nosso objeto trata-se então de uma condensação material das relações contraditórias (que, ao invés de organizar as relações de força no poder, faz o oposto) que configuram, em um plano seguinte, o jogo dessas contradições dentro da materialidade do Estado e torna possível, por mais paradoxal que seja, a sua função organizacional (Poulantzas, 2000, p. 153) como estrutura complexa. É adequado colocar que, portanto, o processo de esmaecimento das

7. Poulantzas (2000) assinala que o Estado nem sempre precisa mentir, mistificar ou ocultar suas intenções propositalmente. 
intenções do Estado e da relação entre seus aparelhos e a ordem social que germina sua concepção de interesse nacional.

Para concluir uma abordagem adequada sobre o Estado é preciso agora conectar as informações reunidas neste item à dimensão internacional da unidade estatal. Note que ao fazê-lo, assumirei uma concepção complementar à ortodoxia teórica das Relações Internacionais sobre o Estado. Portanto, ao invés de recorrer ao ente estatal como ator principal em uma ordem hierárquica nas Relações Internacionais, ou então, ator que divide o cenário global com uma paleta difusa de outros atores. Perceberemos o Estado e outras entidades que interagem no palco internacional como expressões diretas da determinação estrutural burguesa ${ }^{[8]}$, mas quanto a isto anoto que, a partir daqui, vou me apropriar do termo Estado apenas para fins práticos seguimos, portanto, considerando o primado de classes como inerente ao ente estatal nas Relações Internacionais.

Ao fim e ao cabo, quando referimo-nos à atuação internacional de um Estado quer dizer que este está imerso num ambiente competitivo com seus análogos. A prioritate metam de um ente estatal é apropriar-se de sua atuação internacional e assim, obter vantagens e recursos para consolidar, manter e aperfeiçoar seu status e, por fim, mobilizar recursos para a dimensão doméstica (Halliday, 2007, p. 98), este processo envolve também a possibilidade do emprego da força como instrumento de solução de problemas externos, ou seja

[...] um Estado pode apropriar-se de território, ir à guerra, buscar um acordo [...] para ganhar vantagem doméstica, enquanto pode promover a industrialização, introduzir a mudança educacional, aumentar impostos ou tratar melhor uma minoria étnica para atingir objetivos internacionais (Halliday, 2007, p. 98).

Portanto, nota-se que a atuação do Estado em duas dimensões é uma via de mão dupla, entretanto, com os mesmos fins - legitimação e consolidação doméstica. Noto isto porque uma atuação internacional eficiente é capaz de mobilizar recursos e aumentar a credibilidade doméstica enquanto promover um desenvolvimento interno, eficiente e compatível com as carências nacionais, pode acrescer o reconhecimento e a credibilidade internacional e, portanto, e novamente, consolidar a posição doméstica - meios diferentes e de alimentação recíproca, porém com os mesmos fins. É claro, aqueles que dominam e controlam o poder, assinala Halliday (2007), tem muito a ganhar perseguindo essas estratégias (Halliday, 2007, p. 98). Entretanto, é preciso anotar que a ação em duas dimensões envolve processos e cálculos estratégicos distintos visto que, na dimensão interna, o Estado é aquele que detém o monopólio "legítimo" do uso da força como mantedor da ordem, por outro lado, face ao ambiente externo, colide com outras entidades estatais que dispõe da força e estão determinados a usá-la caso necessário, portanto

8. O processo que discuti ao longo do item ilustra a determinação estrutural a qual me refiro - podemos também substituir determinação por condensação, como utilizado por Poulantzas (2000). 
Trata-se, a rigor, de duas estruturas antagônicas de prática da violência entre os homens, num caso, artificial e civilizada, monopolizada pelo Estado e, no outro, natural, compartilhada pelo conjunto de Estados [...] na dicotomia paz e guerra (Espinosa, 2011, p. 97).

Não se pode deixar de anotar um elemento importante neste processo, portanto, note que a dupla dimensão da ação estatal oferece alguns dilemas. Ao elevar, desproporcionalmente, pressões internas para fins internacionais, o bloco no poder corre o risco de entrar em descrédito e choque com a sociedade civil, por outro lado, uma atuação desequilibrada visando grandes obtenções de vantagens para a dimensão doméstica pode levar um Estado ao choque, por vezes destrutivo, com seus análogos (Halliday, 2007, p. 98).

Portanto, é importante perceber o peso da atuação bidimensional da atuação estatal e as estratégias a ela atribuídas visto que, os que detém o poder político ou estão a ele associados quase sempre tendem a mobilizar recursos internacionais para suprimir ou suplantar problemas domésticos. É preciso considerar que - até mesmo para retornar às bases do que foi proposto pelo item "de baixo para cima, de dentro para fora" - (I) os entes de poder político ou a eles associados, por vezes, mobilizam esses recursos a fim de resolver problemas econômicos ou de legitimidade política no interior de um Estado (principalmente quando se está em descrédito ou em situação de sensibilidade com a sociedade civil); e (II) o mesmo ocorre quando um movimento social ou indivíduo está vis-à-vis com o Estado (Halliday, 2007, p. 98). Quanto ao primeiro evento podemos mencionar mobilização de apoio bélico (obtenção de armas ou apoio de natureza militar), econômico (acordos com empresas multinacionais), ou apoio político (celebração de tratados internacionais, obtenção de apoio moral para um processo de legitimação). Certamente o segundo caso - agentes da sociedade civil frente ao Estado - é mais complexo visto que indivíduos têm menor capacidade de mobilizar recursos internacionais, e também domésticos, do que possui o ente estatal.

Para fins de variar a discussão e ilustrar a dinâmica debatida no parágrafo acima, podemos mencionar exemplos bastante próximos à nossa realidade. A começar pelo segundo, que é mais palatável, podemos nos apropriar do evento envolvendo o ex-presidente do Brasil, Luís Inácio "Lula" da Silva, que recorreu ao Comitê de Direitos Humanos da Organização das Nações Unidas contra o juiz federal Sérgio Moro, acusando-o de violar os direitos humanos após uma condução coercitiva (despeito que o ex-presidente jamais se negou a depor $)^{[9]}$. Outro exemplo próximo que pode ilustrar, desta vez a primeira dinâmica do parágrafo acima, é o pacote de privatizações de alguns aeroportos brasileiros, encabeçado pelo "presidente" Michel Temer, que garantiu uma entrada relativamente intensa de investimentos ao longo do período de

9. Folha de São Paulo, 2016. Ex-presidente Lula recorre à ONU contra decisões do juiz Sérgio Moro. Disponível em: <http://www1.folha.uol.com.br/poder/2016/07/1796366-lula-recorre-a-onu-contra-juiz-sergio-moro> acesso em: 29 de outubro, 2017. 
concessão $^{[10]}$ - o objetivo principal do pacote de privatizações é angariar recursos para conseguir legitimidade doméstica e credibilidade entre os parceiros internacionais. Ambos os exemplos apresentados acima exprimem a dinâmica bidimensional de um Estado e como seus associados recorrem à dimensão internacional face, tanto a problemas de legitimidade política, como de situação contenciosa entre sociedade civil e Estado.

\section{O materialismo histórico e a crítica à Política Internacional}

Os comunistas se recusam a dissimular suas opiniões e seus fins. Proclamam abertamente que seus objetivos só podem ser alcançados pela derrubada violenta de toda a ordem social existente. Que as classes dominantes tremam à ideia de uma revolução comunista! Nela os proletários nada têm a perder a não ser os seus grilhões. Têm um mundo a ganhar.

Proletários de todos os países, uni-vos! (Marx \& Engels, 2005, p. 69)

O conhecido final do Manifesto Comunista, de Marx e Engels, traz consigo uma reflexão implícita que ao leitor, por vezes, passa despercebida. Até a publicação do panfleto, em 1848, as duas grandes ondas revolucionárias da primeira metade do século oitocentista haviam sido violentamente sufocadas (Hobsbawm, 1986, cap. 6). É evidente que Marx percebeu um detalhe importante: as classes dominantes dos países europeus tinham relações de solidariedade bastante estreitas e a união entre essas classes era o que as mantinha no poder e lhes fornecia a capacidade de resposta ampla e rápida às movimentações operárias. Com certeza não é à toa ou por pura retórica que Marx e Engels proclamaram a tão conhecida frase "proletários de todos os países, uni-vos". Ao fazê-lo, clamam pelo advento da solidariedade da classe operária a nível internacional e tal clamor serviu de ponto de partida para os diversos marxistas que se propuseram a entender a política internacional a partir da dedução de dois instrumentos básicos que são, ao mesmo tempo, crítica às tradições clássicas no debate das Relações Internacionais: a admissão da dimensão histórica para análise e a conexão entre as dimensões política e econômica. Antes de desenvolver conceitualmente os dois pressupostos, coloco-me a responder uma possível dúvida do leitor: que tem a ver os dois elementos com o clamor do manifesto? A resposta é similar para ambos os pressupostos, visto que nascem da mesma observação. Cabe dizer sobre o primeiro é que a relação de solidariedade entre as classes dominantes ultrapassa as fronteiras, essas relações convergem em vista a um problema comum que é a luta de classes e, portanto, a estrutura das forças produtivas; sobre a segunda, é a relação intima entre Estado, burguesia e propriedade.

Os dois pressupostos anunciados acima são os que têm oferecido as ferramentas para um ponto de partida aos marxistas que estudam e analisam a política internacional. Sobre a incorporação da dimensão histórica como ferramenta primeira de

10. G1 Economia, 2017. Para Temer, país recupera a credibilidade internacional com leilão de aeroportos. Disponível em: <https://g1.globo.com/economia/noticia/pais-reconquistou-credibilidade-internacional-com-leilao-de-aeroportos-diz-temer> acesso em: 29 de outubro, 2017. 
análise, trata-se de entender como as forças produtivas se organizam, seu modo de produção e como são as dinâmicas das relações de produção e os fatores que organizam as relações de dominação. É fundamental uma compreensão primeira destes fenômenos visto que, para compreender as relações políticas entre os Estados, é preciso entender como foram e estão organizadas as estruturas das relações de produção sob determinado período histórico (Vigevani et al, 2011, p. 129) - vamos nos concentrar apenas no bloco histórico da economia mundial capitalista - pois as forças produtivas capitalistas englobam todo o mundo civilizado, ou seja, os eventos dentro e fora das entidades estatais são fundamentalmente derivados das relações de forças entre classe dominante e classe dominada. Em síntese, estes elementos reforçam a necessidade de analisar a "dinâmica das relações sociais de produção para o melhor entendimento da realidade" (Marx apud Vigevani et al., 2011, p. 130), isso quer dizer que as relações internacionais são a totalidade de um grande quadro de relações sociais que exigem a compreensão do estágio de desenvolvimento das forças produtivas (Rosenberg apud Vigevani et al., 2011, p. 130).

Este pressuposto traz consigo uma crítica contundente às correntes tradicionais das Relações Internacionais referente às unidades de análise, por exemplo, o Realismo/neorrealismo, conhecido pela análise estatocêntrica ou o liberalismo/neoliberalismo, que inclui uma gama mais difusa de unidades de análise (como as instituições internacionais). As correntes de vanguarda são de caráter altamente positivista, isto quer dizer que muito se tem dedicado a simplesmente observar os problemas do sistema internacional a partir das relações entre Estados, apresentando análises superficiais, tendo pouco a oferecer sobre a origem dos grandes dilemas nas relações interestatais e, além disto, extraíram a questão do modo de produção capitalista do debate sobre as determinações do comportamento interestatal na política internacional (Teschke \& Lacher apud Vigevani et al., 2011, p. 121) - isso implica que as referidas correntes não foram capazes de compreender os significados das novas forças que desestabilizaram o mundo no final do século XX, enquanto o realismo se transformou em uma teoria paliativa para alguns problemas, o neoliberalismo não conseguiu compreender, ou mesmo prever, os problemas que gestaram as crises do liberalismo econômico (Vigevani et al., 2011, p. 122) —, o marxismo inverte os termos de análise ao colocar como prioritária a análise das estruturas sociais dominantes, derivando disso as relações entre os Estados (Vigevani et al., 2011, p. 119), esta inversão nos permite ir à raiz das relações que determinam a política internacional.

Sobre o segundo pressuposto, a conexão entre as dimensões econômica e política, trata-se da "aglutinação analítica" entre Estado (o público/político) e a economia (o setor privado/burguesia). Aparentemente, o afastamento entre Estado e negócios é fruto da chegada da burguesia ao status de dominação após a Revolução Industrial e Revolução Francesa. Em termos puramente liberais, a lógica mais eficiente é a redução da interferência política no mercado, agravando as possibilidades do triunfo do sistema capitalista (Wallerstein, 2000, p. 144), entretanto, nestes termos, os principais objetivos de um capitalista são (I) otimizar os lucros e (II) assegurar a acumulação "contínua e incessante". Entretanto, esses objetivos operam numa lógica contraditória: no primeiro, o afastamento dos tentáculos reguladores do Estado é 
fundamental para o processo de extração da mais-valia, domínio privado, arranjos de mão de obra mais barata e, quando não, buscá-la em outro território, no segundo, o Estado pode ser um bom garantidor em duas ocasiões-chave (Wallerstein, 1997, pp. 253-260) - a formação de monopólios e facilitador da externalização dos custos - é visível, portanto, a grande interdependência entre Estado e burguesia visto que, por outro lado, o bloco no poder também precisa da burguesia para lhe conferir legitimidade e isso só pode acontecer mediante o poder ideológico e concessões das classes dominantes (a primeira, inerente à lógica gramsciana da disseminação de valores e costumes, a outra, as concessões que foram incorporadas aos Estados na formação dos welfare states) que conferem ao bloco no poder uma maior estabilidade na condução política diante das massas. Portanto, as relações internas entre Estado e burguesia "estão submersas e não podem ser percebidas" (Rupert apud Vigevani et al., 2011, p. 134) porque:

[...] a emergência de uma forma institucional que distingue a esfera do Estado da esfera da economia, nesse sentido, seria uma abstração necessária para a consolidação e para a perpetuação do sistema capitalista (Vigevani et al., 2011, p. 136).

As correntes tradicionais das Relações Internacionais evidentemente não estão preocupadas com a relação Estado-economia e, em função disto, fadadas a encobrir a totalidade complexa do panorama analítico. Isso acontece porque a lógica de rational choice, presente em ambas as tradições clássicas, nega a correlação entre Estado e burguesia e inviabiliza a compreensão da política internacional mais próxima da concretude e, portanto, nas palavras de Vigevani et al. (2011), "resulta na perda de alcance analítico das teses elaboradas pelas escolas dominantes da disciplina" (Vigevani et al., 2011, p. 137).

A desconsideração dos dois pressupostos discutidos acima é, segundo Wallerstein (2000), consequência de uma cisão dos diversos ramos das ciências sociais. $O$ problema apresentado é que, em função disto, as áreas do conhecimento se dispersam da totalidade complexa do entendimento enquanto deveriam fazer exatamente o contrário, visto que são disciplinas perfeitamente interdependentes (Wallerstein, 2000, pp. 130-137). Esta cisão produz um problema amplamente notável e constrangedor, trata-se da incapacidade de entender amplamente das raízes dos novos paradigmas (visto que tais paradigmas demandam dos intelectuais uma avaliação dinâmica e ampla) e a ausência de uma análise eficiente a ser oferecida resulta num outro problema particularmente constrangedor: a legitimação do status quo - para Wallerstein (2000) este é o grande trunfo para a sobrevivência do liberalismo mas deixaremos esta discussão para uma outra ocasião.

O grande problema das escolas tradicionais das Relações Internacionais é a inclinação, quase unanime, na resolução de problemas tópicos. Note que isto não se pode traduzir para outra coisa se não o fato de que as correntes realistas e liberais estão mais interessadas na manutenção da ordem vigente, oferecendo-lhes paliativos, do que resolver, ao fim e ao cabo, os grandes dilemas da política internacional - o risco da guerra, da dominação etc. No fim das contas, entre as duas correntes tradicionais, 
a produção teórica tem seus fins idênticos enquanto diferem apenas nos meios, ou seja, as conclusões acabam por ser sempre as de demonstrar como funciona e como o sistema internacional atual deve ser mantido ou, em alguns casos, como deve ser reordenado (Voigt, 2007, pp. 107-109). Outra grande questão que deve ser levantada, ainda sobre a "interessante" convergência entre as correntes tradicionais é que seus principais expoentes estão diretamente ligados aos quadros de recrutados dos Estados do centro da economia mundial capitalista, corporações e organizações internacionais que, portanto, não se deve deixar de considerar um interesse evidente desses Estados e organizações de uma articulação coerente com a ordem vigente que não deve ser substancialmente transformada ou eliminada, mas periodicamente reestruturada e adaptada aos novos paradigmas (Voigt, 2007). A reivindicação de imparcialidade - de um lado, o realismo, argumentando sobre seu rigor empírico e estruturalista, de outro, o liberalismo, articulando-se como visão universal, "não-alinhada" aos interesses de corporações ou centros econômicos - não esconde a coincidência das duas tradições na clara defesa dos interesses hegemônicos do capitalismo ou dos Estados centrais em manter e legitimar a ordem vigente (Voigt, 2007), tratando-se, portanto, da relação entre os detentores de poder e a ciência que lhes servem à forma mais adequada.

A crítica marxista às escolas tradicionais das Relações Internacionais não se resume, obviamente, tão somente a isto. Tudo o que já fora aqui debatido sobre Estado ou sobre os pressupostos de análise tem potencial para desconstruir as abordagens positivistas da política internacional, entretanto, não podemos deixar de lado outro elemento que tem legitimado a hegemonia das vertentes clássicas que é o conceito de anarquia. O princípio de sistema internacional anárquico pressupõe que os Estados convivam sob igualdade formal, ou seja, ausente de qualquer estrutura jurídica robusta e que detenha monopólio legítimo da força como imperativo regulador dos entes estatais - daí partiria a necessidade do direito internacional e das instituições para construir uma ordem harmônica e cooperativa, no caso dos liberais, ou da intervenção estratégica e constante armamento dos Estados, no caso dos realistas. Parece um ótimo álibi para oferecer instrumentos e resoluções para a conservação da ordem. A concepção de sistema anárquico, note bem, não é por toda incorreta, entretanto, omite as relações de dependência e dominação econômica e social entre os Estados, mas isto, contudo, não significa que as correntes tradicionais não levem em conta as assimetrias no momento da análise (Vigevani et al., 2011, p. 115), entretanto, isto não muda o fato de que a lógica de anarquia encobre o cerne das relações materiais pois:

[...] o que distingue a forma moderna do poder geopolítico não é o fato deste ser exercido por uma pluralidade de unidades independentes (anarquia em geral), mas o fato de já não incorporar relações interpessoais de dominação (o que elimina a independência formal dos dominados) sendo impessoal, mediado por coisas (Rosenberg apud Vigevani et al., 2011, p. 124).

Esta discussão abre precedente também para a concepção de hegemonia - que presta o papel de reprodutor central da ordem. Entretanto, não se pode divergir em 
larga escala das tradições clássicas, visto que a hegemonia é, em definições mais enxutas, o Estado que detém recursos para projetar o poder hegemônico ao redor do globo, entretanto, marxistas como Robert Cox avaliam o hegemon sob uma ótica gramsciana de hegemonia adaptada às relações internacionais. Segundo Vigevani (2011):

O conceito de hegemonia surge como explicativo não só do conflito entre Estados e das relações de dominação, mas também dos outros aspectos que determinam as relações de poder: as relações econômicas, culturais, ideológicas. Essas relações estabelecem-se sobre bases profundas, sobre as estruturas que permeiam a organização social e o desenvolvimento do processo histórico. A hegemonia global começa com a expansão de uma hegemonia estabelecida no âmbito nacional (Vigevani et al., 2011, p. 125).

A discussão sobre hegemonia é de suma importância, visto que é geralmente o elemento regulador de uma ordem que opera sob ausência de jurisdição ou monopólio da força, para tanto, de caráter anárquico. A relação entre as duas discussões é bastante clara: uma hegemonia global expressa fundamentalmente a reprodução e manutenção da ordem internacional, visto que a difusão da ideologia dominante possibilita a instituição de organizações intergovernamentais e mecanismos que estabelecem regras gerais de comportamento para os Estados e forças da sociedade civil que atuam no âmbito interno dos entes estatais, ou seja, regras que suportam, reproduzem e legitimam o modo de produção dominante (cuja ordem do sistema internacional deriva) (Cox \& Sinclair apud Vigevani et al., 2011, p. 125).

Não que o marxismo desconsidere a lógica de anarquia jurídica, tampouco desconsidere a lógica da balança de poder - que é inerente a organização de um sistema internacional cuja ausência de uma estrutura jurídica é o elemento que impera -, entretanto, estes são detalhes secundarizados visto que o sistema internacional e sua organização, sob a lógica de um quadro maior de relações sociais, é resultado dessas relações sociais e das relações de forças produtivas da economia mundial capitalista, portanto, o sistema internacional é também um arranjo das diversas relações de forças e de dominação.

Finalmente, sintetizando, o materialismo histórico tem muito a oferecer para a análise das relações internacionais - não só tem a oferecer, como aquilo que oferece é uma avaliação ampla da totalidade complexa que envolve a política internacional - porque oferece instrumentos rebuscados para apreciar as relações sociais, o modo de produção e uma avaliação sólida das relações de força que determinam as características fundamentais da disciplina (Vigevani et al., 2011, p. 116).

\section{Ferramentas para análise da estrutura internacional}

No artigo Production, Power and World Order: Social forces in the making of history, de Robert W. Cox ${ }^{[1]}$ o autor desenvolve um sistema teórico e metodológico para a análise das Relações Internacionais. Em um primeiro momento, Cox (1986) considera importante uma avaliação das estruturas históricas das (I) forças sociais, (II)

11. Incorporado ao livro Neorealism and its critics, de Robert O. Keohane em 1986. 
da natureza do Estado e (3) das ordens mundiais, para um segundo momento, o autor considera importante uma avaliação categórica das forças em interação com a estrutura, portanto, (I) as capacidades materiais dos Estados, (II) a ideologia e (III) as instituições (Cox, 1986, pp. 218-225). Discutiremos os tópicos a seguir para preparar o terreno da discussão principal deste trabalho, lembrando que o objetivo deste ensaio não é uma discussão exaustiva de cada um dos pontos levantados, portanto procurarei ser breve.

Como vimos no item sobre a questão do Estado ${ }^{[12]}$, as forças sociais que estão sendo consideradas aqui são aquelas inerentes ao modo de produção capitalista. $\mathrm{Ou}$ seja, a contraditória relação entre burguesia e proletariado - as relações de produção são aquelas determinadas pela dominação de uma classe sobre outra. Portanto, em linhas gerais, o que nos interessa saber é a relação entre a classe dominante e o Estado, o que também definimos no Item 3 como aquela relação simbiótica para a manutenção e reprodução da dominação e da ordem social capitalista. Portanto, em resumo, é importante lembrar que a classe dominante não necessariamente governa, mas domina, portanto, o Estado é expressão dessa relação de forças - das relações de classe, das relações entre classe dominante e Estado e das relações entre aparelhos do Estado. Em função disto, em poucas palavras, o Estado é o vetor institucional e político dos interesses burgueses. Ou seja, o sistema internacional pode ser considerado como um quadro maior de forças das interações sociais, onde um ente estatal tem o papel de canalizar e intermediar os interesses da classe dominante doméstica com as classes dominantes de outros lugares, desempenhando, portanto, uma atuação entre a estrutura internacional e a configuração local de forças (Cox, 1986, p. 225) - neste caso, o poder de um Estado e suas capacidades materiais são, acima de tudo, resultados destes processos sociais.

O conjunto dos primeiros elementos, discutidos acima, nos permite entender de que maneira os Estados se dispõem e se relacionam com outros no sistema internacional. Vamos agora debater o segundo conjunto de elementos.

Este segundo conjunto de elementos é inerente às questões de estrutura e ordem sistêmica, ou seja, a condição dos Estados dentro desta estrutura depende da sua condição dentro destes itens. (I) as capacidades materiais, segundo Cox, são reflexos da capacidade de um Estado em produzir e destruir (Cox, 1986, p. 218). Note que, portanto, este elemento envolve diretamente uma relação entre Estado e a burguesia interna, ou seja, a produção e extração da mais-valia - a produção garante ao ente estatal os suprimentos domésticos necessários e uma boa base material para exportações, ou seja, o permite perseguir uma balança comercial mais equilibrada, e com isto, um bom posicionamento na economia internacional capitalista. A capacidade destrutiva envolve, não só a força bélica de um Estado, mais também o desenvolvimento tecnológico. Ambos podem ser utilizados para forçar um resultado na política internacional mediante emprego da violência.

12. Item 3. O Estado: "de baixo para cima, de dentro para fora". 
Sobre (II) o elemento ideológico, trata-se de um sistema de ideias que legitimam a atuação do Estado ${ }^{[13]}$ e podem ser destacados de duas maneiras: (a) "uma noção compartilhada da natureza das relações sociais, que tende a perpetuar hábitos e comportamentos"[14] (Cox, 1986, p. 218), ou seja, a ideia de que a natureza humana é nefasta e que precisa ser comandada pelos entes estatais, autoridades existentes num determinado território (Cox, 1986, p. 218); (b) um conjunto de ideias compartilhadas que legitimam a ordem social, como por exemplo, a ideia de justiça, bens públicos e etc. A conjugação destes dois elementos constitui uma base ideológica mais simples que permite legitimar a ação do Estado, entretanto, para uma atuação internacional de peso, estes grupos de ideias precisam ser reproduzidos na estrutura internacional como extensão do ideário interno. Isso significa que uma hegemonia, apenas consegue manter uma atuação legítima na estrutura se conseguir se projetar de maneira a cristalizar sua imagem como referência ou parâmetro de comportamento social, produtivo, de valores e etc. Entretanto, estes últimos (que compõe o quadro "b" de elementos ideológicos) são palco de muitas controvérsias porque geralmente se choca com as ideologias particulares de algumas culturas (Cox, 1986, p. 219).

O último elemento é o (III) as instituições. Em linhas gerais, as instituições são meios de perpetuar e dar estabilidade a uma ordem particular - no caso das Relações Internacionais, da estrutura interestatal (Cox, 1986, p. 219).

As instituições refletem as relações de poder dominantes em seu ponto de origem e tendem, pelo menos inicialmente, a incentivar as imagens coletivas consistentes com essas relações de poder (Cox, 1986, p. 219) ${ }^{[15]}$.

Portanto, além de reproduzir as relações de poder, os interesses hegemônicos e a ordem social, as instituições condicionam a ideologia e o poder material capaz de influenciar o desenvolvimento e projeção da ideologia dominante. Contudo, as instituições propõem meios de diálogo para um conflito a fim de minimizar o uso da força, o que reproduz e reforça, estruturalmente o poder ideológico e material dominante (Gramsci apud Cox, 1986, p. 219).

Delineamos, portanto, os elementos necessários de análise, o que faremos agora é construir o nosso cenário de avaliação com base no que foi discutido sobre Cox (1986) e admitiremos a lógica em que se estrutura a teoria do sistema mundial capitalista em Wallerstein.

\section{O sistema-mundo capitalista: globalização e instituições internacionais}

Partindo da compreensão atual da relação assimétrica entre os Estados num mundo globalizado, ou seja, apesar de interdependentes, alguns entes estatais possuem maior poder de barganha ou recursos de poder do que outros, começaremos a montar nossa área de trabalho de uma forma mais pragmática. Vamos delinear este palco

13. Joseph Nye Jr. Conceitua a capacidade de cooptação, de promoção de influência e ideias como soft power.

14. Tradução do autor.

15. Tradução do autor. 
admitindo a tese da divisão internacional do trabalho inerente à estrutura capitalista, que fundamenta a teoria wallersteiniana (Martins, 2015, p. 96), ou seja, podemos compartimentar o mundo em três "estamentos" hierárquicos: os Estados centrais, semiperiféricos e periféricos.

A lógica por trás destes estamentos é relativamente simples: os (I) Estados centrais, desempenhando seu papel na (a) economia internacional, são aqueles que se ocupam da produção dos bens de alto valor agregado, na (b) política, são capazes de expandir sua influência e domínio além de suas fronteiras, ou seja, são estados de forte influência, e por fim, na (c) cultura, possuem forte identidade nacional e são capazes de expandir esta identidade como referencia para os outros Estados. Os (II) Estados semiperiféricos são aqueles que desempenham um papel intermediário entre periferia e centro, ou seja, nos três elementos levantados (econômico, político e cultural), são aqueles que relacionam-se de maneira periférica com os Estados centrais e de maneira central com os Estados periféricos. Em suma, são "Estados-tampão", que não permitem que a força dos Estados centrais incidam de maneira destrutiva nos Estados periféricos e servem de barragem para os problemas da periferia, fazendo com que esses problemas não incidam diretamente nos Estados centrais (Martins, 2015, p. 101). Ao fim e ao cabo, os semiperiféricos são aqueles que possuem uma industrialização de baixo valor tecnológico agregado, que detém controle da política interna mas não exercem influencia de peso externamente, possuindo uma identidade cultural e nacional mediana. Por fim, os (III) Estados periféricos são aqueles que desempenham um (a) papel econômico relevante na produção de produtos primários (commodities) e não detém mão de obra especializada, na (b) política, possuem pouco controle da política interna e tampouco exercem influência externa, na (c) cultura, não possuem ou possuem identidade nacional fragmentada, prevalecendo apenas as identidades étnica ou religiosa (Martins, 2015, p. 100), ou seja, possuem mão de obra e recursos naturais abundantes, entretanto, não possuem capital para aproveitar produtivamente estes recursos (Martins, 2015, p. 103) - sendo inundados pelo capital estrangeiro.

A relação de interdependência entre esses estamentos estatais dá-se basicamente pela divisão internacional do trabalho, ou seja, os Estados centrais suprem os semiperiféricos e periféricos com produtos de alto valor agregado, enquanto a semiperiferia e a periferia suprem os Estados centrais com commodities, produtos primários ou de baixo valor agregado. A relação delineada anteriormente - de interdependência e divisão internacional do trabalho - é resultado de uma globalização que se intensifica e, em termos gerais, levando as relações de força e de produção de um Estado para além de suas fronteiras.

Os principais aspectos da globalização que nos interessam são (I) a organização global de produção que são, em linhas gerais, as redes transnacionais de produção, que facilitam a produção e trânsito de vários produtos em locais distintos, que oferecem vantagens de custos em geral (mão de obra, mercados, impostos e etc.) e (II) setor financeiro global, ou seja, um sistema robusto de transações financeiras (dinheiro, crédito ou ações) que facilitam as transações de custos de bens e serviços internacionais (Cox, 1993, p.260). A convergência destes dois elementos é o que configura 
uma economia global e que existe conjuntamente com uma economia internacional estabelecida por transações através das fronteiras, ambas reguladas por acordos e relações entre os entes estatais (Cox, 1993, p. 260).

Vamos admitir que a definição que vimos acima seja a máscara para o modelo de Wallerstein. Portanto, a dinâmica entre os Estados centrais, semiperiféricos e periféricos é essencialmente potencializada pela globalização. A lógica é que, individualmente, os Estados centrais concorrem entre si enquanto coletivamente extraem recursos dos semiperiféricos e periféricos - isto potencialmente contribui para a manutenção de poder entre centro e periferia. A dinâmica da globalização, podemos simplificar os termos daqui pra frente, entre Estados "dominantes" e "dominados", entretanto, apresenta uma expressão contraditória: enquanto de um lado há o desejo da manutenção do status quo, de outro, há o desejo de expansão do status econômico. Esta contradição implica que os Estados estão constantemente competindo para expandir ou para manter seu poder ou status de dominante, e por vezes, isto pode levá-los ao choque e, por fim, pôr em risco a ordem global. A compartimentação entre os estamentos não é determinante, ou seja, não significa que os Estados não possam ascender de periferia para semiperiferia, ou de semiperiferia para centro, ou até mesmo sofrer um declínio de centro para semiperiferia, entretanto, a tendência é que o regime de exploração seja uma ferramenta forte de manutenção do status quo.

Para que a manutenção da ordem prevaleça, é preciso um conjunto de instrumentos legitimadores da hierarquia ${ }^{[16]}$ entre os Estados - ou seja, a relação entre dominantes e dominados -, do fenômeno da globalização e do poder hegemônico. Vamos nos ater aos que, para nós, são os principais instrumentos: as normas, regimes e instituições internacionais e a ideologia hegemônica.

Para organizar o raciocínio, vou compartimentá-lo desta forma: o Estado é uma superestrutura doméstica formada pela infraestrutura domésticas (as relações produtivas e de força domésticas, bem como os aparelhos estatais), ao mesmo tempo, sua expressão no sistema internacional é uma infraestrutura (ou seja, o Estado, com relação à estrutura internacional, é uma unidade de infraestrutura); o sistema internacional, portanto, é uma superestrutura (composta por infraestruturas que são expressão das suas relações domésticas) (Sarfati, 2005, pp. 140-142). As relações entre as infraestruturas da (e com a) superestrutura internacional são expressas pelas contradições entre os Estados (as mesmas que descrevi dois parágrafos acima). Esta relação dialética implica que haja uma força sintetizadora daquelas contradições e, creio ser suficiente para pensar esta força como uma outra superestrutura, interna à estrutura internacional, ou seja, refiro-me às instituições internacionais.

As instituições internacionais, sob o manto da superestrutura internacional, tem um papel mantedor e legitimador da ordem, visto que canalizam as condições da superestrutura (relação entre dominantes e dominados) sob um manto normativo e ideológico (Wallerstein apud Martins, 2015, p. 99). Este manto a que me refiro, normativo e ideológico, desempenha a função de manutenção, reprodução e legitimação de duas formas simultâneas, bastante parecidas: um conjunto de normas e um con-

16. Recapitulando: centrais, periféricos e semiperiféricos. 
junto de valores. O primeiro provém legitimidade jurídica às relações de dominação e exploração enquanto o segundo provém os valores e concepções morais que tornam legítimos, não somente as relações de exploração e dominação, mas as normas fornecidas pelo elemento normativo (Cox, 1986, p. 119). Esses valores são geralmente fundamentados pelos liberais no argumento de que é possível alcançar o desenvolvimento e a plenitude se houver a cooperação entre os Estados, visto que são entes interdependentes. Portanto, em função de ilustrar minha colocação, parafraseando a cosmologia: podemos entender as instituições internacionais como um subsistema cosmológico $^{[17]}$ da superestrutura internacional, ou seja, os Estados na condição de centralidade constroem a burocracia normativa das instituições de maneira a reproduzir os valores e a ideologia hegemônica, colocando os Estados periféricos e semiperiféricos na condição de órbita a esses valores, o que facilita na incorporação desses Estados à zona de influência hegemônica. Convenhamos, é uma forma interessante de pensar a estratégia para ganhar legitimidade dentro das instituições.

Portanto, a configuração produzida, que é necessária para a reprodução da economia mundial capitalista é este sistema interestatal composto por unidades soberanas e organizados por um conjunto de instituições que asseguram a manutenção da ordem internacional. Para legitimar estas estruturas, a configuração social capitalista corroeu as diversas comunidades que condicionavam determinadas nações históricas e criou uma nova rede de comunidades nos moldes liberais (Wallerstein, 2000, p. 122). A interdependência criada neste processo de reconfiguração do sistema-mundo para uma economia mundial capitalista nos permite observar a correlação entre centro, semiperiferia e periferia a partir de uma ilustração cosmológica - como vimos no parágrafo anterior, a relação de interdependência entre os entes estatais é tão forte que, dada a divisão internacional do trabalho e a constituição de monopólios nos Estados centrais, os Estados periféricos e semiperiféricos passam a orbitar a zona de influência dos centros.

Podemos perceber, portanto, que as instituições internacionais tem papel fundamental na reprodução do sistema-mundo capitalista e de legitimação da condição de dominação sob o espectro da hegemônico. É possível recorrer a exemplos bastante relevantes do nosso tempo - e o faremos. A Organização Mundial do Comércio (OMC), por exemplo, é caro a esta garantir o funcionamento do comércio mundial nos moldes liberais, ou seja, trata-se de uma estrutura que estabelece as normas sob o risco de pena, caso haja descumprimento (Martins, 2015, pp. 100-102); órgãos credores internacionais, como o Banco Mundial (BM) e o Fundo Monetário Internacional (FMI), que emprestam fundos a juros em escala estratosférica, impõe restrições econômicas e exigem uma reestruturação da política econômica e fiscal dos Estados contemplados, ou seja, as condicionalidades impostas pelos credores das instituições financeiras reproduzem o caráter da dominação e da dependência, da divisão internacional do trabalho e, consequentemente, da manutenção do sistema-mundo capitalista (Martins, 2015, p. 103). Podemos recorrer a outros exemplos de institui-

17. Esta analogia foi inspirada no texto Cosmologias do Capitalismo, de Marshall Sahlins (In: Cultura na Prática). 
ções que não são fundamentalmente credoras, como a Organização das Nações Unidas (ONU), que possui papel fundamental na construção de políticas, economias e sociedades pautadas no liberalismo e na democracia liberal (Bellamy \& Williams apud Martins, 2015, p. 103), ao fim e ao cabo, é um instrumento fundamental da reprodução hegemônica que reproduz também as necessidades políticas, econômicas e estratégicas dos Estados centrais (Cravo apud Martins, 2015, p. 103).

Entretanto, as instituições, bem como a ordem liberal como um todo, começaram a perder legitimidade (principalmente depois da crise econômica global de 20072008) visto que, somado aos diversos problemas internos dos Estados (educação, infraestrutura, políticas públicas e etc.), começou a ser percebido por boa parte das populações que as elites domésticas dos países retinham grande parte dos ganhos com a globalização. Esta configuração problemática foi a centelha para a ascensão brutal de figuras e levantes populistas e nacionalistas ao redor do globo, colocando em cheque não só a globalização, mas as instituições da ordem liberal, os imigrantes, os acordos de integração e etc. (Nye, 2017, s.p.). Como assinalou Keohane e Colgan, em um artigo publicado ainda em 2017 na Foreign Affairs:

Aqueles de nós que não só analisaram a globalização e a ordem liberal, mas também a celebraram, compartilham alguma responsabilidade pelo aumento do populismo. Nós não prestamos atenção suficiente à maneira que o capitalismo sequestrou a globalização. Elites econômicas criaram instituições internacionais para servir seus próprios interesses e criar ligações mais firmes entre eles e os governos. Como é de se esperar, as pessoas foram deixadas de fora (Keohane \& Colgan, 2017, pp. 1-2) ${ }^{[18]}$.

À luz destes eventos, Hobolt (2016) também explica o fenômeno do Brexit: as pessoas passaram a se mostrar cada vez mais céticas quanto à integração, uma vez que os britânicos foram surpreendidos com uma taxa de desemprego massiva, pela crise dos imigrantes e pela falta de acesso às vantagens da integração, portanto, houve um forte avanço do discurso nacionalista e populista, principalmente entre as classes mais baixas (Hobolt, 2016, s.p.). O discurso em outros países, principalmente na semiperiferia, não tem sido muito diferente dos dois primeiros: as pessoas começaram a perceber a globalização como uma invasão ao seu espaço, a entrada de estrangeiros como sinônimo do desemprego e as instituições internacionais como expressão dos interesses das elites. Os trabalhos de Sara B. Hobolt, Joseph Nye Jr., Robert O. Keohane e Jeff Colgan são substancialmente semelhantes e confirmam que, em função dos elementos apresentados ao longo deste parágrafo, a classe trabalhadora passou a ser extremamente cética com relação às instituições liberais e à globalização, fundamentalmente, é esta classe que lutou de forma mais dura para construir os recursos que permitiram o funcionamento da ordem liberal e suas instituições e foi, por estas últimas, esquecida (Keohane \& Colgan, 2017, s.p.) e começaram a acreditar que esta ordem e suas instituições são manipuladas pelas elite global - o que dá o título do trabalho de Keohane e Colgan "The liberal order is rigged".

18. Tradução do autor. 
O que podemos pensar sobre o retrato global apresentado pelos autores mencionados acima é que, como afirmou Wallerstein, após longas datas de um processo intenso e forçado de universalização da ordem liberal capitalista, de ideologia e dominação hegemônica, das crises cíclicas do capitalismo que ganharam tamanha intensidade - e nos colocou num estado de turbulência e de possível transição -, estamos presenciando um colapso, uma convulsão cultural ao redor do mundo tentando resistir a essas pressões (Wallerstein, 2000, p. 123) — os fundamentalismos religiosos, as guerras entre etnias no mundo não-ocidental, os movimentos antissistêmicos, antirracistas, antissexistas e etc. Essas rebeliões ao redor do globo não são, de forma alguma, iguais, entretanto, são a consequência comum do processo implacável de universalização dos moldes liberais que, segundo Wallerstein, oprime em nome de uma "lógica universal e racionalizadora" (Wallerstein, 2000, p. 123).

\section{Considerações finais}

Finalmente, creio que este trabalho conseguiu atingir os objetivos propostos na introdução. É evidente que o materialismo histórico tem muito a oferecer para a análise das Relações Internacionais porque oferece um instrumental rebuscado que permite a observação dos fenômenos mais íntimos ao campo da ação humana, fazendo com que a análise chegue o mais próximo possível da concretude e permita ao pesquisador não apenas compreender os fatos em sua complexidade, mas oferecer alternativas a eles.

Ao longo deste trabalho, conseguimos compreender de forma relevante as críticas que recaem sobre o marxismo enquanto análise da política internacional e dar atenção considerável às lacunas consideradas por Bobbio, por exemplo. Apreendemos de forma razoavelmente boa a concepção de Estado, como expressão de relações, na tradição marxista e conectamos sua dimensão doméstica à internacional com certo sucesso. Passamos também de forma bastante enxuta e elementar por uma reflexão sobre a guerra e o que leva os Estados ao emprego da força. Com certeza estes dois elementos nos ofereceram uma bagagem rica para prosseguir a uma análise crítica dos debates das relações internacionais, sendo possível demonstrar aquilo que foi afirmado acima: o marxismo oferece ferramentas robustas e ricas para a análise concreta da política internacional e tem condições sólidas de participar, mais do que como coadjuvante, da arena epistemológica da disciplina de Relações Internacionais.

Nos últimos itens, conseguimos perceber com clareza o emprego do materialismo histórico na análise da política internacional. Creio que este trabalho conseguiu cumprir seus objetivos conforme proposto, uma vez que trouxe elementos bastante sólidos para observar as relações inerentes ao sistema de Estados, que serviram de sustentação e confirmaram as hipóteses propostas na introdução: podemos considerar as instituições internacionais como subsistemas oriundos das contradições do sistema-mundo capitalista e foi possível compreender as contradições da globalização. Portanto, este trabalho se mostrou bastante positivo com relação à sustentação do ensaio sobre as instituições de um mundo globalizado e também na explicação das implicações produzidas pelas relações contraditórias que a globalização impõe. 


\section{Referências}

Anderson, P. (1985). A Crise do Marxismo: Introdução a um debate contemporâneo. São Paulo: Brasiliense.

Berringer, T. (2011). Estado e relações internacionais: uma comparação crítica entre Hans Morgenthau e Nicos Poulantzas (Dissertação de mestrado). Unicamp, Campinas, Brasil.

Berringer, T. (2015). A Burguesia Brasileira e a Política Externa nos Governos FHC e Lula (1. ${ }^{\mathrm{a}}$ ed.). Curitiba: Appris.

Bobbio, N. (2006). Nem com Marx, Nem contra Marx. São Paulo: Unesp.

Codato, A. (2008). Poulantzas, o Estado e a Revolução. Crítica Marxista, 27, 82.

Cox, R. W. (1986). Social Forces, States and World Orders. In R. O. Keohane (Ed.), Neorealism and its Critics. New York: Columbia University Press.

Cox, R. W. (1993). Structural issues of global governance: implications for Europe. In S. Gill, Gramsci, Historical Materialism and International Relations (pp. 249-254). New York: Cambridge University Press.

Cox, R. W. (2007). Gramsci, Hegemonia e Relações Internacionais: um ensaio sobre o método. In S. Gill (Org.), Gramsci, Materialismo Histórico e Relações Internacionais (pp. 101-123). Rio de Janeiro: Editora da UFRJ.

Espinosa, A. R. (2011). A Sombra dos Leviatãs - um estudo crítico dos desencontros entre as faces amistosa e crispada do Estado sob as globalizações e as guerras do século XXI (Tese de doutorado). Universidade de São Paulo, São Paulo, Brasil.

Espinosa, A. R. (2014). Marxismo e Relações Internacionais. In A. L. V. Neves (Org.), Teoria das Relações Internacionais: As Questões Mundiais em Debate. Petrópolis: Editora Vozes.

Halliday, F. (2007). Repensando as Relações Internacionais (2. ${ }^{\mathrm{a}}$ ed.). Porto Alegre: UFRGS.

Hobolt, S. B. (2016). The Brexit Vote: A divided nation, a divided continent. Journal of European Public Policy, 23(9), 1259-1277.

Hobsbawm, E. J. (1986). A Era das Revoluções: 1789-1848. Lisboa: Presença.

Kautsky, K. (1903). The Social Revolution. London: The Twentieth Century Press.

Keohane, R. O., \& Colgan, J. (2017). The Liberal Order is Rigged. Foreign Affairs, 96 (3).

Krader, L. (1983). Evolução, Revolução e Estado: Marx e o pensamento etnológico (2 ed.). In E. J. Hobsbawm, História do Marxismo: O Marxismo no tempo de Marx (pp. 263-300). Rio de Janeiro: Paz e Terra.

Lenin, V. I. (2005). O Imperialismo: Fase superior do capitalismo (3. ${ }^{\text {a }}$ ed.). São Paulo: Centauro.

Martins, J. R. (2015). Immanuel Wallerstein e o Sistema-mundo: uma teoria ainda atual? Iberoamérica Social: Revista-red de Estudios Sociales, (V), 95-108.

Marx, K. (1888). Teses sobre Feuerbach. In F. Engels, Ludwig Feuerbach e o Fim da Filosofia Alemã Clássica. Estugarda, Alemanha: Engels.

Marx, K. \& Engels, F. (2005). Manifesto Comunista. São Paulo: Boitempo.

Marx, K. \& Engels, F. (2010). A Ideologia Alemã. São Paulo: Centauro.

Mészáros, I. (1983). Marx “filósofo”. In E. J. Hobsbawm, História do Marxismo: O Marxismo no tempo de Marx (2. ed.). Rio de Janeiro: Paz e Terra. 
Mészáros, I. (2004). O Poder da Ideologia. São Paulo: Boitempo.

Miliband, R. (1972). O Estado na Sociedade Capitalista. Rio de Janeiro: Zahar.

Nogueira, J. P. \& Messari, N. (2005). O Marxismo. In J. P. Nogueira \& N. Messari, Teoria das Relações Internacionais: Correntes e Debates. Rio de Janeiro: Elsevier.

Nye, J. (2017). Will the liberal order survive? The History of an Idea. Foreign Affairs, 96(1), $10-16$.

Passos, R. (2014). Clausewitz, Marx, Engels e Lênin: rupturas, continuidades, ou parentescos intelectuais na relação entre guerra e revolução?. VI Seminário Internacional de Teoria Política do Socialismo - UNESP.

Poulantzas, N. (2000). O Estado, O Poder, O Socialismo (4 ed.). Rio de Janeiro: Graal.

Sarfati, G. (2005). Teoria das Relações Internacionais. São Paulo: Saraiva.

Silva, D. P. \& Rodriguez, V. (2015). O Estado em Poulantzas: Uma análise da constituição da hegemonia na sociedade de classes. VIII Colóquio Internacional Marx Engels - Cemarx.

Vigevani, T. et al. (2011). A Contribuição Marxista para o estudo das Relações Internacionais. Lua Nova, 83, 111-143.

Voigt, M. (2007). A Análise dos Sistemas - mundo e a política internacional: uma abordagem alternativa das teorias das relações internacionais. Textos de Economia, 10(2), 101-118.

Wallerstein, I. (1997). A Reestruturação Capitalista e o Sistema Mundial. Perspectivas, 20/21, 249-267.

Wallerstein, I. (2000). The Essential Wallerstein. New York: The New Press. 


\section{Sobre o autor}

BRUNO M. FALCETTI é concluinte do Bacharelado em Relações Internacionais pela Escola Paulista de Política, Economia e Negócios da Universidade Federal de São Paulo (EPPEN-UNIFESP), tendo passado inicialmente pela Universidade Federal da Paraíba (UFPB) em João Pessoa, na região nordeste do Brasil. É membro do grupo de pesquisa "Conflitos Armados, Massacres e Genocídios” e, atualmente, participa da construção do Laboratório de Análise em Segurança Internacional e Tecnologias de Monitoramento (LASINTec). O artigo apresentado para a Revista Portuguesa de Ciência Política é resultado dos estudos realizados pela cadeira "Materialismo histórico, dialético e Relações Internacionais", que fora ministrada pelo falecido Professor Dr. Antônio Roberto Espinosa - o até então orientador do presente autor.

\footnotetext{
About the author

BRUNO M. FALCETTI is concluding his Bachelor's degree in International Relations at the Paulista School of Politics, Economy and Business from the São Paulo Federal University (EPPEN-UNIFESP), he had initially studied at the Paraíba Federal University (UFPB) in João Pessoa, Northeast Brazil. He is a fellow member of the research group "Armed Conflicts, Massacres and Genocides" and, currently, participates on the building of the Laboratory of Analysis on International Security and Monitoring Technologies (LASINTec). The paper presented for the Portuguese Journal of Political Science is a result of studies made by the dearly departed professor Dr. Antônio Roberto Espinosa - former mentor of the author.
} 